rights. The psychiatrists' risk calculations formed the basis of the court's finding that there was a duty to protect Ms Rabone's 'right to life' under Article 2 of the European Convention, and the breach lay in the hospital's failure to detain her against her will.

The decision in Rabone v. Pennine Care NHS Foundation Trust means that risk calculations have the potential to affect the rights of all psychiatric patients to access leave or to refuse hospital admission or lengthy hospital stays where their suicide risk is thought to be 'real' - that is 'significant' and not 'remote' or 'fanciful' - at the time they request to leave the hospital.

The principal duty of the expert witness is to provide accurate, objective and unbiased testimony about complex matters before the court. Now that hospitals have a clear responsibility to protect psychiatric patients thought to be at immediate risk of suicide, if necessary by invoking coercive powers to detain and treat, psychiatric experts must make realistic estimations of the likelihood of suicide based on the facts of the case, knowledge of the literature and careful avoidance of hindsight bias.

1 Rabone v. Pennine Care NHS Foundation Trust [2012] UKSC 2

2 Rabone v. Pennine Care NHS Trust [2009] EWHC 1827 (QB).

3 Large M, Ryan C, Nielssen O. The validity and utility of risk assessment for inpatient suicide. Australas Psychiatry 2011; 19: 507-12.

4 Ziskin J. Challenging Clinical Judgement. Law and Psychology Press, 1991.

5 Fischhhoff B. Hindsight not equal to foresight: the effect of outcome knowledge on judgement under uncertainty. Qual Saf Health Care 2003; 12: $304-12$.

Matthew Large is a Clinical Senior Lecturer in the School of Psychiatry, University of New South Wales, Sydney, Australia, email: mmbl@ bigpond.com; Christopher James Ryan is a Senior Clinical Lecturer in the Discipline of Psychiatry and the Centre for Values, Ethics and the Law in Medicine at the University of Sydney, Australia; Sascha Callaghan is a lawyer and Lecturer in the School of Public Health and Community Medicine, University of New South Wales, and a doctoral scholar at the Centre for Values, Ethics and the Law in Medicine, University of Sydney.

doi: $10.1192 / p b .36 .6 .236$

\section{We wouldn't judge a patient for being mentally unwell, so why judge ourselves?}

I thought the paper by an anonymous doctor with a mental illness ${ }^{1}$ was a breath of fresh air and highlighted key common problems surrounding medicine and mental health. I could fully empathise with the author.

I became unwell while at medical school and initially refrained from seeking help, fearing that I would be asked to leave. In fact, when the truth came out the school was extremely supportive and I regret not seeking help earlier.

I agree with many of the comments made regarding treatment by other professionals. My husband is a doctor, which doubled the amount of doctors we know. Usually, I was left with little option but to be treated by someone I know. Sometimes this worked out well, and sometimes it left me feeling foolish and upset. I feel 'stigma' is much the essence of our own prejudices and that especially as medics we tend to set the bar rather high for ourselves. For this to be broken down, the more openly mental illness is discussed in medicine, particularly within training schemes and in medical school, the less daunting it becomes. This will of course involve medics speaking out about their illnesses and acknowledging that we are not infallible, yet perhaps more vulnerable.

It was indicated to me on many occasions by healthcare professionals that I must avoid admission as an in-patient 'as it would not be good for me as medic'. I can see why the act of protection was thought best for me. My husband too had extra pressure placed on him to care for me at home. In the end the inevitable came; I became extremely unwell and had a lengthy in-patient stay. I do often wonder whether my illness would have taken the same progression if I had been admitted earlier.

One benefit of working within the National Health Service is the access to the occupational health service and so I have had treatment funded that I would not have got otherwise (e.g. psychotherapy).

Regarding the General Medical Council references, the situation is incredibly delicate. When you have worked so hard for many years and your career could be in jeopardy, you may think twice before turning to a professional body. Yet would you shy away from seeking help if you broke a bone? I very much think honesty is the best policy and if at the end of the day you are not fit to work (for whatever reason), then patients' safety is paramount. However, admitting there are problems early on and being honest and seeking help through the correct avenues leaves you in good stead. I think the more medics do this the better. We can prove you can have mental illness, recover and continue a career in medicine and then speak out, which holds great hope. I also believe that suffering from any illness can provide you with valuable skills and empathy.

I wish the author well and thank you for making that step at being a medic and speaking out.

1 Anonymous. Medicine and mental illness: how can the obstacles sick doctors face be overcome? Psychiatrist 2012; 36: 104-7.

Victoria A. Ribbons, mental health service user/final year medical student (currently interrupting studies), Peninsula College of Medicine and Dentistry, UK, email: victoria.ribbons@students.pms.ac.uk

doi: $10.1192 / \mathrm{pb} .36 .6 .237$

\section{Correction}

Evaluation of teaching an integrated case formulation approach on the quality of case formulations: randomised controlled trial. The Psychiatrist 2012; 36: 140-145. The last line of the second introductory paragraph should read: 'We are not aware of any published UK studies on this subject; however, in an unpublished British study, M.A. examined 150 new assessment letters, of which only $6 \%$ included any formulation, showing that case formulation is rarely attempted in routine psychiatric practice.' In addition, the Case Formulation Scale is available as an online supplement to this correction.

doi: $10.1192 / p b .36 .6 .237 a$ 